\title{
Effects of 5-Aminolevulinic Acid on Chlorophyll, Photosynthesis, Soluble Sugar and Flavonoids of Ginkgo biloba
}

\author{
Feng XU'1, Shuiyuan $\mathrm{CHENG}^{2}$, Jun ZHU³ ${ }^{3}$, Weiwei ZHANG ${ }^{1}$, Yan WANG ${ }^{1}$ \\ ${ }^{1}$ Yangtze University, College of Horticulture and Gardening, Jingzhou 434025, China; xufeng198@126.com \\ ${ }^{2}$ Huanggang Normal University, College of Life Science and Engineering, Huanggang 438000, China; s_y_cheng@sina.com \\ ${ }^{3}$ Zhongshan Torch Polytechnic, Department of Bio-medicine, Zhongshan 528436, China
}

\begin{abstract}
The flavonoid content determines the quality of Ginkgo biloba that can be increased by using of plant growth regulators. The objective of study was to observe the effect of 5-aminolevulinic acid (ALA), a key precursor in the biosynthesis of porphyrins and a new plant growth regulator, on photosynthetic rate, chlorophyll and soluble sugar content, flavonoid accumulation, and flavonoid enzyme activity in $G$. biloba leaves. The ginkgo seedlings were grown in greenhouse conditions under low levels $\left(10\right.$ and $\left.100 \mathrm{mg} \mathrm{l}^{l^{-1}}\right)$ of foliar application of ALA. Photosynthetic rates of leaves increased significantly at day 4 in response to both ALA concentrations and remained elevated as compared to control for further 12 days. Chlorophyll and soluble sugar contents were significantly increased by day 4 and continued to increase by day 16 ; however, $\mathrm{Chl}$ a/b ratio remained unchanged. Total polyphenols, flavonoids, and anthocyanins, phenylalanine ammonia-lyase (PAL), chalcone synthase (CHS) and chalcone isomerase (CHI) activities were increased from day 4 to 16 after ALA treatment. The increase in chlorophyll and soluble sugar contents, and activities of flavonoid enzymes (PAL, CHS and CHI) were likely to be closely associated with improvement of the accumulation of total polyphenols, flavonoids, anthocyanins and advance of leaf quality by ALA treatment. Foliar treatment with a low concentration of ALA therefore, might provide a useful means of improving pharmacological properties of $G$. biloba leaves.
\end{abstract}

Keywords: 5-aminolevulinic acid, chlorophyll, flavonoids, Ginkgo biloba, photosynthesis, soluble sugar

\section{Introduction}

Flavonoids protect plants against UV-B radiation and pathogen attack, attract pollinating insects, and act as signal molecules for initiating plant-microbe symbiotic associations (Winkel-Shirley, 2002). They are beneficial for human health by virtue of their antioxidative, antimutagenic, and anticarcinogenic effects (Rice-Evans et al., 1997; Smith and Luo, 2004). The occurrence of coronary heart disease and of certain cancers has been inversely associated with the ingestion of flavonoids (Formica and Regelson, 1995; Steinmetz and Potter, 1996; Lin and Tang, 2006). Cheng et al. (1999) estimated the average intake of potentially healthy flavonoids as $25 \mathrm{mg}$ per day and cited that oranges, apples, and $G$. biloba tea were the main dietary contributors for intake of human diet in the Jiangsu province of China.

Standardized preparations of G. biloba, Egb761, contain $24 \%$ flavonoids, which have several pharmaceutical properties for human health (van Beek, 2002). In G. biloba, flavonoids located primarily in the leaf are important determinants of its pharmacological properties and determine the quality characteristics of ginkgo tea or extract. Therefore, much interest is currently centered on increasing the medicinal value of ginkgo leaves by increasing their flavonoid contents. In vivo experiments on ginkgo leaves indicated that externally supplied ABA, cycocel, ethephon, and metal ions could increase flavonoid contents (Cheng et al., 2004; Wang et al., 2007).

In plants, 5-aminolevulinic acid (ALA) is a key precursor in the biosynthesis of porphyrins such as chlorophyll and heme. ALA is synthesized from glutamate in a reaction involving a glutamyl-tRNA intermediate and requiring ATP and NADPH as cofactors; its formation is the rate-limiting step in chlorophyll biosynthesis (von Wettstein et al., 1995). In recent years, application of low concentrations of exogenous ALA has been found to promote plant growth, development and responses to environmental stresses (Roy and Vivekanandan, 1998), such as crop productivity (Hotta et al., 1997), stress tolerance (Hotta et al., 1998; Watanabe et al., 2000; Wang et al., 2004a; Sun et al., 2009; Naeem et al., 2011; Liu et al., 2011), and recovery of growth under herbicide toxicity stress (Zhang et al., 2008). ALA was also found to increase anthocyanin accumulation related to phenylalanine ammonia-lyase (PAL) induction (Wang et al., 2006). Thus, ALA appears to have potential as a non-toxic endogenous substance for improving agricultural production (Wang et al., 2003). Recently, it has been reported that foliar ALA application could improve the photosynthesis and flavonoid accumulation in 
42

G. biloba (Wang et al., 2008). However, the physiological mechanism responsible for the promotion by ALA of the increase of total flavonoid content has not yet been elucidated. Present studies were to demonstrate evidence that ALA promoted the accumulation of total polyphenols, flavonoids, and anthocyanins, which is associated with contents of chlorophyll, carbohydrate and the activities of enzymes involved in flavonoid biosynthesis.

\section{Materials and methods}

\section{Chemicals}

Folin-Ciocalteu phenol reagent was purchased from Fluka (Steinheim, Germany). All other chemicals were obtained from Sigma (St. Louis, MO, USA). Water was passed through a Milli-Q water purification system (TGI Pure Water Systems, USA) prior to use.

\section{Plant materials and ALA treatment}

Seeds of Ginkgo biloba cv. 'Jiafoshou' were sown in pots $(50 \times 30 \times 7 \mathrm{~cm})$ filled with sandy soil. At the two-three leaf stage, three hundred seedlings of uniform size were transferred to a greenhouse and irrigated daily with $1 / 2$ Hoagland solution. At the 7 to 8-leaf stage, all plants were transferred to a growth chamber under a $12 \mathrm{~h}$ photoperiod $\left(25^{\circ} \mathrm{C}, 500 \mu \mathrm{mol} \mathrm{m} \mathrm{s}^{-1}\right)$ at $75 \% \mathrm{RH}$. After eight days, all seedlings were treated by foliar spray with an aqueous solution of ALA (dissolved in acetic acid buffer solution, $\mathrm{pH}$ 4.6, $20 \mathrm{ml} \mathrm{pot}^{-1}$ ) at three concentrations of 0 (control), 10 , and $100 \mathrm{mg} \mathrm{l}^{-1}$. The fourth and fifth leaves were harvested at days $0,4,8$ and 16 for all measurements except photosynthetic rate. Six replications (9 plants/replication) were used per treatment and samples pooled for each measurement.

Measurement of photosynthetic rates, chlorophyll and soluble sugar contents

To measure in vivo photosynthetic rate, the fourth leaf from a 7-8 leaf stage seedling was placed in the cuvette of LI-6400 portable photosynthesis system (Licor, USA). Measurement periods were in the morning from 8:00 to 11:00 am when leaves of $G$. biloba were under a light intensity of $1000 \mu \mathrm{mol} \mathrm{m} \mathrm{m}^{-2}$ and humidity of $60 \%$. Ten independent measurements on 10 uniform seedlings were made on days $0,4,8$, and 16 after ALA treatment.

Chlorophyll content was determined on $100 \mathrm{~g}$ samples from randomly selected fully expanded leaves. Leaf material was cut into $1 \mathrm{~cm}$ pieces, then ground in a mortar (adding liquid nitrogen) and homogenized in cold $\left(4^{\circ} \mathrm{C}\right)$ aqueous $80 \%(\mathrm{v} / \mathrm{v})$ acetone. The homogenate was kept in the dark and centrifuged at $1000 \mathrm{x}$ g for $5 \mathrm{~min}$ to remove the leaf debris. The absorbance of the extract at 647 and $664 \mathrm{~nm}$ was measured with a spectrophotometer (DU 730, Beckman Coulter Inc., USA). Chlorophyll a, b, and the total the extinction coefficients were determined as described by Graan and Ort (1984).
Soluble sugars of fresh leaf tissue were extracted with boiling ethanol/water and analyzed enzymatically as described by Kunst et al. (1984), by using UV spectrophotometer. The concentration of soluble sugars was expressed as a percentage of fresh weight (w/w, FW).

\section{Extraction andanalysis of totalpolyphenols, anthocyanins,} and flavonoids

Five gram sample of fresh leaf tissue was frozen with liquid nitrogen, ground into a fine powder, homogenized in $50 \mathrm{ml}$ of methanol containing $1 \% \mathrm{HCl}$. The solution was sonicated for 20 min with continual $\mathrm{N}_{2}$ gas purging and centrifuged for $15 \mathrm{~min}$ at $12000 \mathrm{xg}$ at $4^{\circ} \mathrm{C}$. The supernatant was filtered through paper filter. The methanol extract was pooled and concentrated. The aqueous residue was extracted with petroleum ether $(3 \times 30 \mathrm{ml})$, to remove pigments and lipids, and solvent residue was then removed under vacuum. The remaining solution was made up to 25 $\mathrm{ml}$ with methanol, and this solution was analyzed for total polyphenols (TP), total flavonoids (TF), and total anthocyanins (TA).

Measurements of TP were carried out according to Arnous et al. (2001) by using the Folin-Ciocalteu reagent. Gallic acid was used as the reference standard and results were expressed as mg gallic acid equivalents (GAE) 100 $\mathrm{g}^{-1}$ fresh weight (FW). TF were measured as described by Cheng et al. (2004) with slight modifications. One milliliter aliquot of extract, appropriately diluted, was mixed with $0.4 \mathrm{ml}$ distilled water in a $1.5 \mathrm{ml}$ microcentrifuge tube. Thirty micro litre of $5 \% \mathrm{NaNO}_{2}$ was added and the mixture was allowed to react for $5 \mathrm{~min}$. Following this, thirty microlitre of $10 \% \mathrm{AlCl}_{3}$ was added and after $5 \mathrm{~min}$. Two hundred microlitre $1 \mathrm{M} \mathrm{Na}_{2} \mathrm{CO}_{3}$ and $0.24 \mathrm{ml}$ distilled water were added and absorbance was measured at $510 \mathrm{~nm}$. Total flavonoid content was calculated from a calibration curve using rutin as a standard and expressed as mg rutin equivalents (RE) $100 \mathrm{~g}^{-1} \mathrm{FW}$. TA were determined as described by Pirie and Mullins (1976) with minor modification. An aliquot of extract $(5 \mathrm{ml})$ was combined with ethanolic $\mathrm{HCl}$ solution $(0.25 \mathrm{M})$ to give a 1:10 dilution. After thorough mixing, the absorbance at $520 \mathrm{~nm}$ was read after $5 \mathrm{~min}$. Total anthocyanin content was determined as $\mathrm{mg}$ cyanin (cyanidin 3-O-glucoside) equivalents (CyE) 100 $\mathrm{g}^{-1} \mathrm{FW}$.

\section{Determination of enzyme activity}

Four gram sample of fresh leaf tissue was homogenized in $12 \mathrm{ml}$ of extraction buffer $(50 \mathrm{mM}$ Tris-HCl buffer, pH 8.9, 15 mM $\beta$-mercaptoethanol, 5 mM EDTA, 5 mM ascorbic acid, $1 \mathrm{mM}$ PMSF, $0.2 \%$, w/v PVP) in a chilled mortar. The homogenate was filtered through four layers of cheesecloth and centrifuged at $12000 \times \mathrm{g}$ for $20 \mathrm{~min}$ at $4^{\circ} \mathrm{C}$. The supernatant was used as a source of crude enzyme for assaying activities of phenylalanine ammonia-lyase (PAL), chalcone synthase (CHS), and chalcone isomerase (CHI). Protein was determined according to the Brad- 
ford method using BSA as a standard (Bradford 1976). PAL (E.C. 4.3.1.5) activity was measured as described by Solecka and Kacperska (2003). One unit of enzyme activity equaled the amount of PAL that produced $1 \mathrm{nmol}$ of cinnamic acid in 1 h. CHS (E.C. 2.3.1.74) activity was measured as according to Xu et al. (2007). CHI (E.C. 5.5.1.6) activity was measured with the method of $\mathrm{Li}$ et al. (2006). CHS and CHI activities were both expressed as unit $\mathrm{mg}^{-1}$ protein.

\section{Statistical analysis}

Data were analyzed with one-way ANOVA using SPSS 11.0 (SPSS Inc., Chicago, Illinois) for Windows and means were compared with Duncan's multiple range test at $P<0.05$. Data represent the means \pm standard errors (SE) of nine independent assays.

\section{Results}

Effect of ALA on leaf photosynthetic rates and chlorophyll and soluble sugar contents

Time-course changes of the photosynthetic rate following 0, 10, and $100 \mathrm{mg} \mathrm{l}^{-1}$ ALA treatment are shown in Fig. 1. Minor changes in photosynthetic rate were observed in the control $\left(0 \mathrm{mgl}^{-1} \mathrm{ALA}\right)$, but the photosynthetic rates in treated samples with 10 and $100 \mathrm{mg} \mathrm{l}^{-1}$ ALA continuously increased from day 4 to 16 and were significantly $(P<0.05)$ higher than the control. Treatment with 10 and $100 \mathrm{mg}$ $1^{-1}$ ALA resulted in increases in photosynthetic rates that were $106.3 \%$ and $198.7 \%$, respectively, of the control rate on day 16.

Tab. 1 shows a gradual increase in chlorophyll contents between day 0 and 16 in response to both concentrations of ALA, while the $\mathrm{Chl} \mathrm{a} / \mathrm{b}$ ratio remained constant. Chlo-

Tab. 1. Effect of 5-aminolevulinic acid (ALA) at 0 (control), 10 and $100 \mathrm{mg} \mathrm{l}^{-1}$ on the chlorophyll (Chl) content of ginkgo leaves (Unit: $\mathrm{mg}^{-1} \mathrm{FW}$ ). Values are the mean of 9 plants

\begin{tabular}{|c|c|c|c|c|c|}
\hline $\begin{array}{l}\text { Days after } \\
\text { teatment }\end{array}$ & Treatment & Chl $a$ & $\mathrm{Chl} b$ & Chl $a+b$ & $\mathrm{Chl} a / b$ \\
\hline \multirow[t]{3}{*}{0} & Control & $0.91 \mathrm{a}$ & $0.43 a$ & $1.31 \mathrm{a}$ & $2.12 \mathrm{a}$ \\
\hline & $10 \mathrm{mgl}^{-1} \mathrm{ALA}$ & $0.92 \mathrm{a}$ & $0.43 a$ & $1.32 \mathrm{a}$ & $2.14 \mathrm{a}$ \\
\hline & $100 \mathrm{mg} \mathrm{l}^{-1} \mathrm{ALA}$ & $0.91 \mathrm{a}$ & $0.42 \mathrm{a}$ & $1.32 \mathrm{a}$ & $2.17 \mathrm{a}$ \\
\hline \multirow[t]{3}{*}{4} & Control & $1.04 \mathrm{c}$ & $0.50 \mathrm{~b}$ & $1.53 \mathrm{c}$ & $2.08 \mathrm{~b}$ \\
\hline & $10 \mathrm{mg} \mathrm{l}^{-1} \mathrm{ALA}$ & $1.23 \mathrm{~b}$ & $0.53 \mathrm{ab}$ & $1.76 \mathrm{~b}$ & $2.32 \mathrm{a}$ \\
\hline & $100 \mathrm{mg} \mathrm{l}^{-1} \mathrm{ALA}$ & $1.35 \mathrm{a}$ & $0.59 \mathrm{a}$ & $1.94 \mathrm{a}$ & $2.29 \mathrm{a}$ \\
\hline \multirow[t]{3}{*}{8} & Control & $1.26 \mathrm{~b}$ & $0.59 c$ & $1.85 \mathrm{~b}$ & $2.14 \mathrm{a}$ \\
\hline & $10 \mathrm{mgl}^{-1} \mathrm{ALA}$ & $1.47 \mathrm{ab}$ & $0.69 \mathrm{~b}$ & $2.16 \mathrm{ab}$ & $2.13 \mathrm{a}$ \\
\hline & $100 \mathrm{mg} \mathrm{l}^{-1} \mathrm{ALA}$ & $1.52 \mathrm{a}$ & $0.72 \mathrm{a}$ & $2.24 \mathrm{a}$ & $2.11 \mathrm{a}$ \\
\hline \multirow[t]{3}{*}{16} & Control & $1.63 \mathrm{~b}$ & $0.73 \mathrm{~b}$ & $2.66 \mathrm{~b}$ & $2.23 \mathrm{a}$ \\
\hline & $10 \mathrm{mgl}^{-1} \mathrm{ALA}$ & $1.98 \mathrm{a}$ & $0.90 \mathrm{a}$ & $2.88 \mathrm{ab}$ & $2.20 \mathrm{a}$ \\
\hline & $100 \mathrm{mg} \mathrm{l}^{-1} \mathrm{ALA}$ & $2.12 \mathrm{a}$ & $0.95 \mathrm{a}$ & $3.07 \mathrm{a}$ & $2.23 \mathrm{a}$ \\
\hline
\end{tabular}

Different letters within a column indicate a significant $(\mathrm{P} \leq 0.05)$ difference by Duncan's multiple rang test

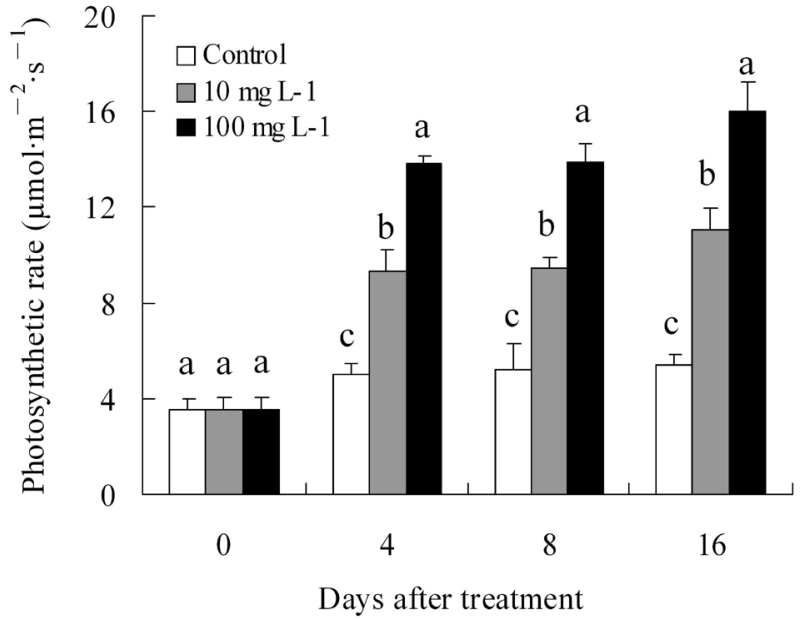

Fig. 1. Effect of 5-aminolevulinic acid (ALA) treatment at 0 (control), 10 and $100 \mathrm{mg} \mathrm{l}^{-1}$ on the photosynthetic rate of ginkgo leaves. Values are the mean of 9 plants and bars represent standard errors. Means with the different letters are significantly different at $P \leq 0.05$ by Duncan's multiple rang test

rophyll content (Chl $a, \mathrm{Chl} b$ and total chlorophyll) was significantly $(P<0.05)$ higher in ALA-treated leaves than in the control. Total chlorophyll content had increased by $21.5 \%$ and $30.1 \%$ by day 16 following treatment with 10 and $100 \mathrm{mgl}^{-1} \mathrm{ALA}$, respectively.

Soluble sugar contents in all leaves, regardless of treatment, increased gradually (Fig. 2). The sugar contents were significantly $(P<0.05)$ higher in leaves treated with 10 and $100 \mathrm{mg} \mathrm{l}^{-1}$ ALA than in the control. At day 16, sugar contents in leaves treated with 10 and $100 \mathrm{mg} \mathrm{l}^{-1}$ ALA conditions were $27.08 \%$ and $54.85 \%$, respectively, higher than control.

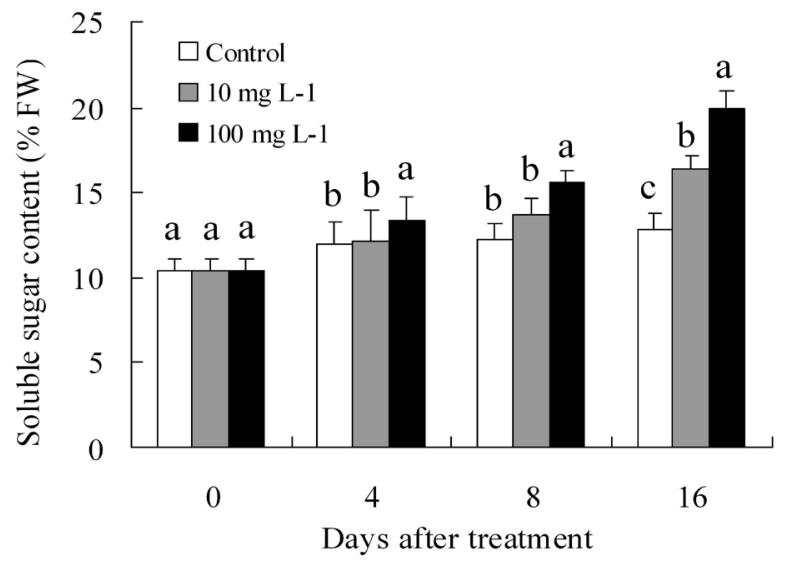

Fig. 2. Effects of 5-aminolevulinic acid (ALA) treatment at 0 (control), 10 and $100 \mathrm{mg} \mathrm{l}^{-1}$ on the soluble sugar content of ginkgo leaves. Values are the mean of 9 plants and bars represent standard errors. Means with the different letters are significantly different at $P \leq 0.05$ by Duncan's multiple rang test 
44

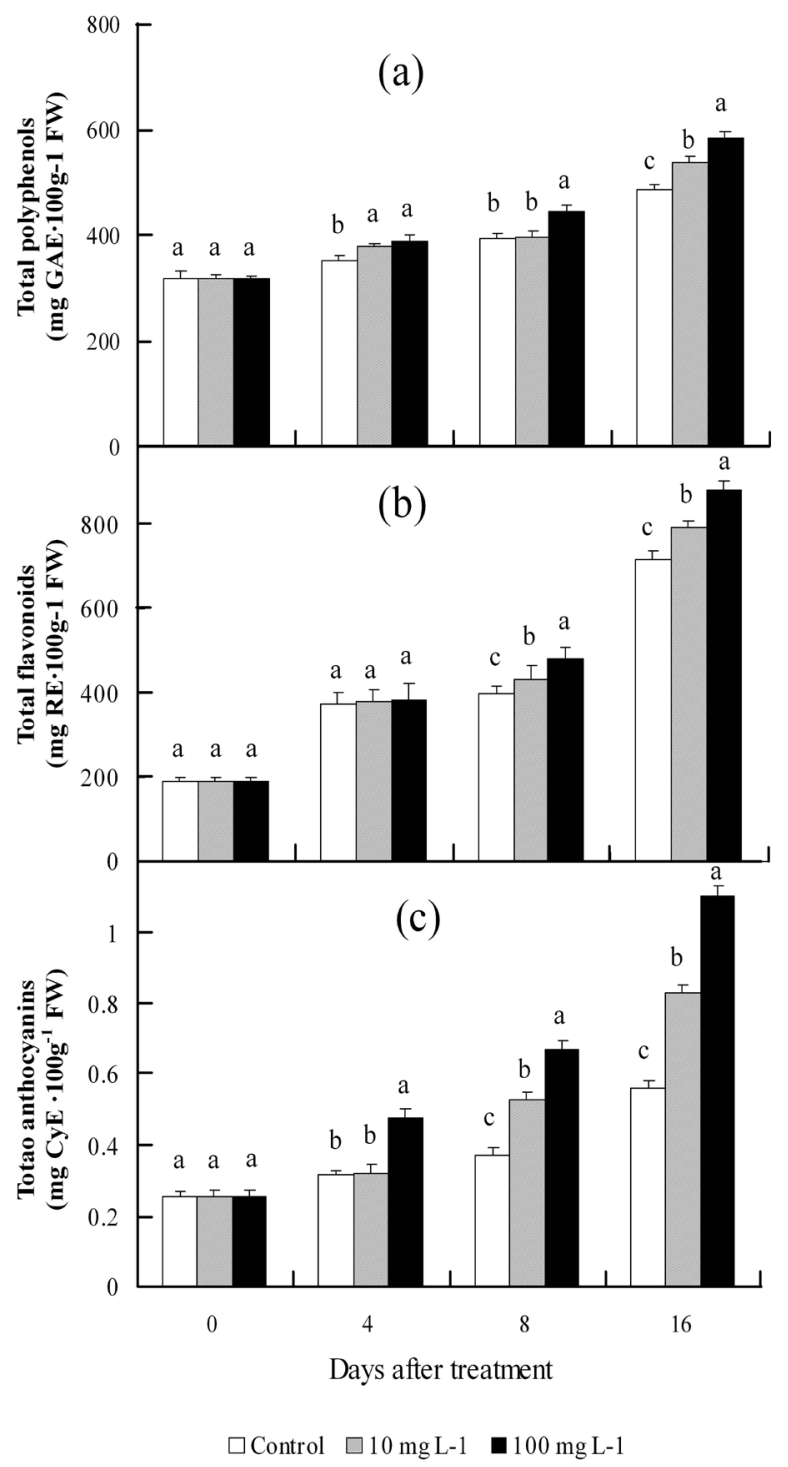

Fig. 3. Effects of 5-aminolevulinic acid (ALA) on 0 (control), 10 and $100 \mathrm{mg} \mathrm{l}^{-1}$ the contents of total polyphenols (a), flavonoids (b) and anthocyanins (c) of ginkgo leaves. Values are the mean of 9 plants and bars represent standard errors. Means with the different letters are significantly different at $P \leq 0.05$ by Duncan's multiple rang test

Effect of ALA on total polyphenols, flavonoids and anthocyanins

The TP contents of all leaves displayed a gradual increase over the duration of the experiment (Fig 3a). However, the TP contents were significantly $(P<0.05)$ higher in ALA-treated leaves than control (except for the $10 \mathrm{mg} \mathrm{l}^{-1}$ ALA treatment at day 8). Treatment with 10 and $100 \mathrm{mg}$ $1^{-1}$ ALA significantly increased $(10.4 \%$ and $20.3 \%$, respectively) TP contents compared to the control at day 16 .

A gradual increase in TF in ALA-treated leaves from day 0 to 8 , followed by a pronounced increase at day 16 was observed (Fig 3b). The TF contents showed no significant

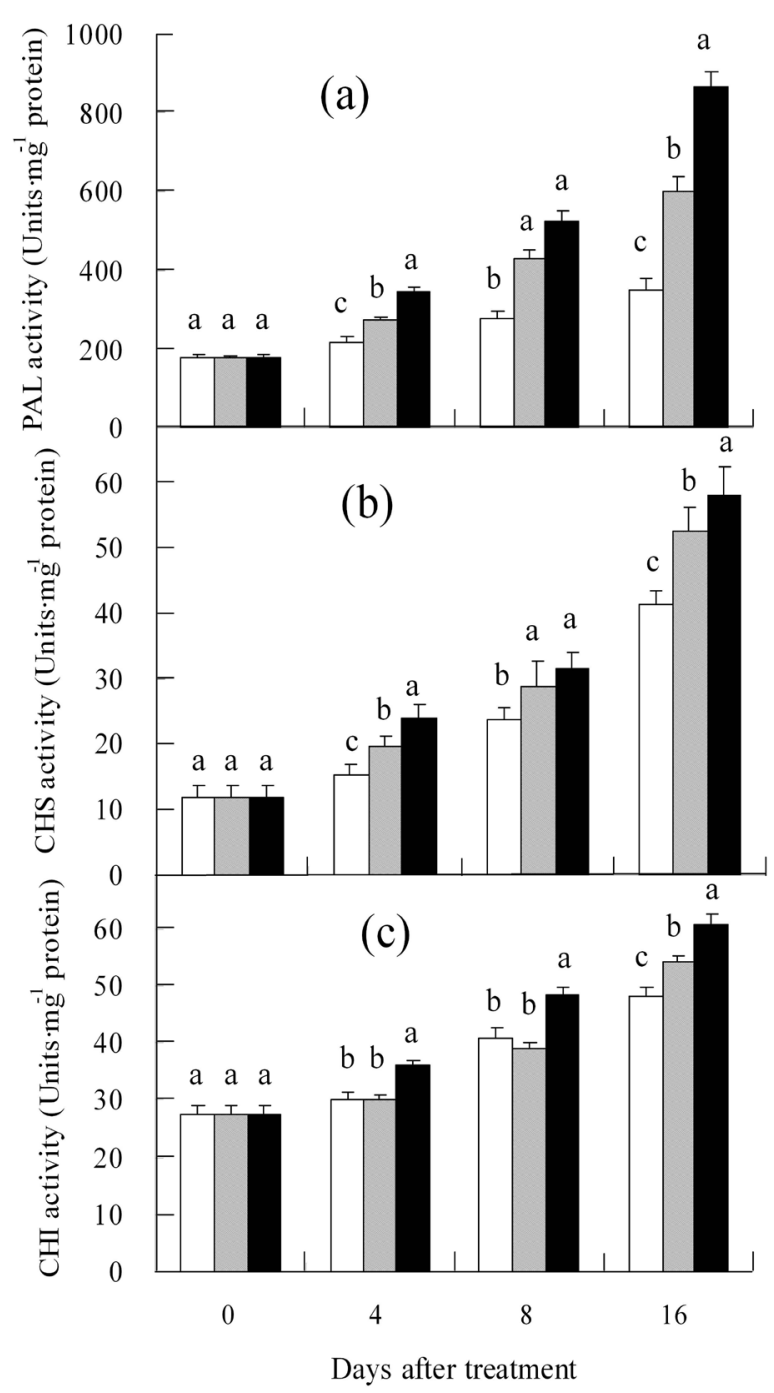

$\square$ Control $\square 10$ mg L-1 $\square 100$ mg L-1

Fig. 4. Effects of 5-aminolevulinic acid (ALA) 0 (control), 10 and $100 \mathrm{mg}^{-1}$ on the activities of PAL (a), CHS (b) and CHI (c) of ginkgo leaves. Values are the mean of 9 plants and bars represent standard errors. Means with the different letters are significantly different at $P \leq 0.05$ by Duncan's multiple rang test

response to ALA application at day 4, but TF of control was significantly lower $(P<0.05)$ than ALA treated leaves at day 8 and 16. At day 8 , the TF contents of 10 and 100 $\mathrm{mg}^{-1}$ ALA-treated leaves were $9.68 \%$ and $21.6 \%$ higher than control, respectively. Furthermore, the TF contents of leaves at 10 and $100 \mathrm{mg} \mathrm{l}^{-1}$ ALA application were respectively $10.6 \%$ and $23.1 \%$ higher than control.

The TA contents were significantly $(P<0.05)$ higher in the ALA-treated leaves (Fig 3c) than control from day 4 to 16. The ginkgo leaves treated with 10 and $100 \mathrm{mg} \mathrm{l}^{-1}$ ALA had significantly higher TA contents, $47.9 \%$ and $96.1 \%$ respectively over the control at day 16 . 


\section{Effect of ALA on PAL, CHS, and CHI activities}

All activities of the three enzymes increased throughout the course of treatment. PAL activity was significantly increased $(P<0.05)$ in ALA treated leaves compared to control, with the $100 \mathrm{mg} \mathrm{l}^{-1}$ ALA treatment showing a greater effect than the $10 \mathrm{mg} \mathrm{l}^{-1}$ ALA treatment (Fig 4). At day 16, an increase in PAL activity above the control of $72.6 \%$ was noted at $10 \mathrm{mg} \mathrm{l}^{-1}$ and $150.1 \%$ at $100 \mathrm{mg}$ $1^{-1}$ ALA treatment (Fig. 4a). CHS activity was also significantly $(P<0.05)$ enhanced above the control level by ALAtreatment. At day 16, CHS activity reached the maximum; the CHS activities of the leaves treated with 10 and $100 \mathrm{mg}$ $1^{-1}$ ALA were $27.4 \%$ and $40.8 \%$ higher, respectively, than control (Fig. 4b). CHI activity of leaves was significantly increased by ALA treatment in a dose-dependent manner (Fig 4c). The CHI activity of the leaves treated with 10 $\mathrm{mg} \mathrm{l}^{-1}$ ALA was significantly higher (12.0\% higher) than control at day 16, but differences observed on day 4 and 8 were not significant $(P>0.05)$. However, CHI activity of the leaves treated with $100 \mathrm{mg} \mathrm{l}^{-1}$ ALA was significantly higher than control from day 4 to 16 , with a maximum increase of $25.5 \%$ at day 16 .

\section{Discussion}

Accumulated evidence suggested that exogenous ALA at low concentrations can promote photosynthesis in some plant species. ALA treatment could improve the biosynthesis of phycocyanin and chlorophyll in algal cells and eventually improve cell growth (Sasaki et al., 1995), and could significantly restore the photosynthetic ability under low light condition in melon (Wang et al., 2004a) and watermelon (Sun et al., 2009). Furthermore, ALA treatment increased the photosynthetic rates as well as the chlorophyll contents in pakchoi (Memon et al., 2009) and oilseed rape (Naeem et al., 2010). The present study also confirmed that photosynthetic rates in ginkgo leaves could be significantly enhanced by foliar application of ALA. As ALA is the first key precursor in chlorophyll biosynthesis, and since the biosynthesis of ALA in plants is the limiting step during tetrapyrrole biosynthesis (von Wettstein $e t$ al., 1995), it is easy to understand why exogenous supply of ALA would result in increased chlorophyll content. In the present study, ALA treatment increased the chlorophyll contents, which would be expected to improve quantum efficiency. The increase in chlorophyll might be associated with the increases in anthocyanin and flavonoid content, as a positive relationship was noted among chlorophyll, anthocyanin, and flavonoid contents (Cheng et al., 2001).

In the present experiment, ALA treatment enhanced leaf soluble sugar content, which is in agreement with earlier reports (Wang et al. 2004a; Zhang et al., 2006), where addition of ALA significantly increased the total soluble sugar content of melon leaves and potato microtubers, respectively. This promotive effect of ALA on soluble sugar content was likely resulted from the increase in carbohy- drates due to increased photosynthesis rates (Hotta et al., 1997).

ALA has been proposed to promote the accumulation of products involved in phenylpropanoid metabolism in plants, for example, apple fruit anthocyanins (Wang et al., 2004b, 2006). Polyphenols, flavonoids, and anthocyanins are all involved in the quality characteristics of ginkgo leaves and their processed products, like GBE761 (van Beek, 2002). The present study showed notable increase in total polyphenols, flavonoids, and anthocyanins contents as expected following ALA-treatment. ALA treatment also significantly induced the activities of PAL, CHS, and $\mathrm{CHI}$ in a concentration-dependent manner in ginkgo leaves. Wang et al. (2006) suggested that ALA could mobilize and regulate the synthesis of phytochrome, as phytochrome activity was believed to regulate flavonoid gene expression in many plant systems (Tobin and Silverthorne, 1985; Awad et al., 2001). A positive relationship has been shown between total polyphenol, flavonoid, and anthocyanin content and the activities of PAL, CHS and CHI in many plants (Ju et al., 1995; Mato et al., 2000; Obinata et al., 2003). Numerous molecular biological studies have also shown that the transcript levels of several genes encoding the enzymes involved in flavonoid and anthocyanin biosyntheses, such as PAL, CHS, and CHI, are positively correlated with the accumulation of flavonoids and anthocyanins (Jaakola et al., 2002; Fischer et al., 2007). Recent findings demonstrated that PAL and CHS were both key regulatory enzymes in flavonoid biosynthesis in G. biloba leaves (Xu et al., 2007; 2008) and observed that ALA could induce the transcription of chalcone isomerase gene $(G b C H I)$, a key gene regulating flavonoid accumulation in ginkgo leaves (Cheng et al., 2011). For these reasons, increases in the total polyphenol, flavonoid, and anthocyanin contents have been assumed to be due to enhanced PAL, CHS and CHI activities as a result of ALA treatment. On the other hand, the increase in these substances may also be associated with the increases in carbohydrate precursors as substrates for phenylpropanoid and flavonoid pathways. Application of ALA could significantly increase soluble sugar contents, as well as polyphenols, anthocyanins, and flavonoids that are synthesized from hexoses through the shikimate and phenylpropanoid pathways (Pirie and Mullins, 1976). Present data indicated promotive effects of ALA on total polyphenol, flavonoid, and anthocyanin contents and on PAL, CHS and CHI activities were dependent on the time and concentration of ALA application.

\section{Conclusions}

From present studies it may be concluded that ALA at low concentrations of 10 and $100 \mathrm{mg} \mathrm{l}^{-1}$ greatly promotes chlorophyll, soluble sugar content, the activities of three flavonoid pathway enzymes (PAL, CHS and CHI), total polyphenol, flavonoid and anthocyanin content in ginkgo 
46

leaves. Since these phytochemicals are often considered as major quality attributes of ginkgo leaves, it is proposed that treatment with low concentrations of ALA may be a useful strategy for improving the health value of ginkgo leaves.

\section{Acknowledgements}

This work was supported by University-Industry Cooperation Fund (CXY2009B009) and Science Foundation of Excellent Young Talents (Q20091201) of Hubei Educational Office, the Program for New Century Excellent Talents in University (NCET-04-0746), the Natural Science Foundation of Hubei Province (2008CDA061), and the Educational Office Key Research Program of $\mathrm{Hu}$ bei Province (Z200627002) of China.

\section{References}

Arnous A, Makris DP, Kefalas P (2001). Effect of principal polyphenolic components in relation to antioxidant characteristics of aged red wines. J Agric Food Chem 49:5736-5742.

Awad MA, Wagenmakers PS, De Jager A (2001). Effects of light on flavonoid and chlorogenic acid levels in the skin of 'Jonagold' apples. Sci Hortic 88:289-298.

Bradford MM (1976). A rapid and sensitive method for the quantitation of microgram quantities of protein utilizing the principle of protein-dye binding. Anal Biochem 72:248254.

Cheng H, Li L, Cheng S, Cao F, Wang Y, Yuan H (2011). Molecular cloning and function assay of a chalcone isomearse gene (GbCHI) from Ginkgo biloba. Plant Cell Rep 30:4962.

Cheng S, Gu M, Shu H (1999). Comment on methods of enhancing flavonoids content of leaf in Ginkgo biloba and their outlook. U.S. Chinese Health Hyg J 2:216-217.

Cheng SY, Wang Y, Li JK, Tao ZY (2001). Study on the relationship between the flavonoids and pigments in Ginkgo biloba leaf. Sci Silvae Sin 37:31-34 (in Chinese).

Cheng S, Wang Y, Fei Y, Zhu G (2004). Studies on the effects of different treatments on flavonoids contents in Ginkgo biloba leaves and their regulating mechamnism. J Fruit Sci 21:116119 (in Chinese).

Fischer TC, Gosch C, Pfeiffer J, Halbwirth H, Halle C, Stich K, Forkmann G (2007). Flavonoid genes of pear (Pyrus communis). Trees-Struct Funct 21:521-529.

Formica JV, Regelson W (1995). Review of the biology of quercetin and related bioflavonoids. Food Chem Toxicol 33:1061-1080.

Graan T, Ort DR (1984). Quantitation of the rapid electron donors to P 700, the functional plastoquinone pool and the ratio of the photosystems in spinach chloroplast. J Biol Chem 259:14003-14010.

Hotta Y, Tanaka T, Takaoka H, Takeuchi Y, Konnai M (1997).
Promotive effects of 5-aminolevulinic acid on the yield of several crops. Plant Growth Regul 22:109-144.

Hotta Y, Tanaka T, Bingshan L, Takeuchi Y, Konnai M (1998). Improvement of cold resistance in rice seedling by 5-aminolevulinic acid. J Pestic Sci 23:29-33.

Jaakola L, Maatta K, Pirttila AM, Torronen R, Karenlampi S, Hohtola A (2002). Expression of genes involved in anthocyanin biosynthesis in relation to anthocyanin, proanthocyanindin, and flavonol levels during bilberry fruit development. Plant Physiol 130:729-739.

Ju Z, Liu C, Yuan Y (1995). Activities of chalcone synthase and UDPGal: flavonoid-3-o-glycosyltransferase in relation to anthocyanin synthesis in apple. Sci Hortic 63:175-185.

Kunst A, Draeger B, Ziegenhorn J (1984). UV-methods with hexokinase and glucose-6-phosphate dehydrogenase, p. 163-172. In: Bergmeyer HU (Ed.). Methods of enzymatic analysis. vol VI. Verlag Chemie, Weinheim.

Li F, Jin Z, Qu W, Zhao D, Ma F (2006). Cloning of a cDNA encoding the Saussurea medusa chalcone isomerase and its expression in transgenic tobacco. Plant Physiol Biochem 44:455-461.

Lin J, Tang C (2006). Determination of total phenolic and flavonoid contents in selected fruits and vegetables, as well as their stimulatory effects on mouse splenocyte proliferation. Food Chem 101:140-147.

Liu D, Pei ZF, Naeem MS, Ming DF, Liu HB, Khan F, Zhou WJ (2011). 5-Aminolevulinic acid activates antioxidative defense system and seedling growth in Brassica napus L. under water-deficit stress. J Agron Crop Sci (in press, doi:10.1111/j.1439-037X.2011.00465).

Mato M, Onozaki T, Ozeki Y, Higeta D, Itoh Y, Yoshimoto Y, Ikeda H, Yoshida H, Shibata M (2000). Flavonoid biosynthesis in white-flowered Sim carnations (Dianthus caryophyllus). Sci Hortic 84:333-347.

Memon SA, Hou X, Wang L, Li Y (2009). Promotive effect of 5-aminolevulinic acid on chlorophyll, antioxidative enzymes and photosynthesis of Pakchoi (Brassica campestris ssp. chinensis var. communis 'Tsen et Lee'). Acta Physiol Plant 31:51-57.

Naeem MS, Jin ZL, Wan GL, Liu D, Liu HB, Yoneyama K, Zhou WJ (2010). 5-Aminolevulinic acid improves photosynthetic gas exchange capacity and ion uptake under salinity stress in oilseed rape (Brassica napus L.). Plant Soil 332:405-415.

Naeem MS, Rasheed M, Liu D, Jin ZL, Ming DF, Yoneyama K, Takeuchi Y, Zhou WJ (2011). 5-Aminolevulinic acid ameliorates salinity-induced metabolic, water-related and biochemical changes in Brassica napus L. Acta Physiol Plant 33:517-528.

Obinata N, Yamakawa T, Takamiya M, Tanaka N, Ishimaru K, Kodama T (2003). Effects of salicylic acid on the production of procyanidin and anthocyanin in cultured grape cells. Plant Biotechnol 20:105-111.

Pirie A, Mullins MG (1976). Changes in anthocyanin and 
phenolics content of grapevine leaf and fruit tissues treated with sucrose, nitrate, and abscisic acid. Plant Physiol 58:468472.

Rice-Evans AC, Miller NJ, Paganga G (1997). Antioxidant properties of phenolic compounds. Trends Plant Sci 2:152159.

Roy CB, Vivekanandan M (1998). Role of aminolevulinic acid in improving biomass production in Vigna catjung, V. mungo and $V$. radiate. Biol Plant 41:211-215.

Sasaki K, Marquez FJ, Nishio N, Nagai S (1995). Promotive effects of 5-aminolevulinic acid on the growth and photosynthesis of Spirulina platensis. J Ferment Bioeng 79:453-457.

Smith JV, Luo Y (2004). Studies on molecular mechanisms of Ginkgo biloba extract. Appl Microbiol Biotechnol 64:465472.

Solecka D, Kacperska A (2003). Phenylpropanoid deficiency affects the course of plant acclimation to cold. Physiol Plant 119:253-262.

Steinmetz KA, Potter JD (1996). Vegetables, fruit, and cancer prevention: a review. J Am Diet Assoc 96:1027-1039.

Sun YP, Zhang ZP, Wang LJ (2009). Promotion of 5-aminolevulinic acid treatment on leaf photosynthesis is related with increase of antioxidant enzyme activity in watermelon seedlings grown under shade condition. Photosynthetica 47:347-354.

Tobin EM, Silverthorne J (1985). Light regulation of gene expression in higher plants. Annu Rev Plant Physiol Plant Mol Biol 36:569-593.

Van Beek TA (2002). Chemical analysis of Ginkgo biloba leaves and extracts. J Chromatogr A 967:21-55.

Von Wettstein D, Gough S, Kannangara CG (1995). Chlorophyll biosynthesis. Plant Cell 7:1039-1057.

Wang LJ, Jiang WB, Zhang Z, Yao QH, Matsui H, Ohara $\mathrm{H}$ (2003). Biosynthesis and physiological activities of 5-aminolevulinic acid (ALA) and its potential application in agriculture. Plant Physiol Commun 39:185-192 (in Chinese).

Wang LJ, Jiang WB, Huang BJ (2004a) Promotion of 5 -aminolevulinic acid on photosynthesis of melon (Cucumis melo) seedlings under low light and chilling stress conditions. Physiol Plant 121:258-264.
Wang LJ, Wang ZH, Li ZQ, Liu H, Liu WQ, Chen ZY, Yan $P$ and Sun DQ (2004b). Effect of 5-aminolevulinic acid on enhancing apple fruit coloration. J Fruit Sci 21:512-515 (in Chinese).

Wang ZH, Tang GH, Li ZQ, Wang LJ (2006). Promotion of 5-aminolevulinic acid and genistein on anthocyanin accumulation in apples. Acta Hortic Sin 33:1055-1058 (in Chinese).

Wang Y, Li L, Xu F, Liu W, Cheng S (2007). Effects of some metal ions on phenylalanine ammonia-lyase activities and flavonoids content of Ginkgo biloba leaves in the potted orchard. J Nanjing Forest Univ 31:68-72 (in Chinese).

Wang Y, Zhu J, Zheng F, Cheng H, Chang J, Xu F, Cheng S (2008). Effect of 5-aminolevulinic acid on photosynthesis and flavonoids content of Ginkgo biloba leaves, p. 651654. In: Tang K, Huang D, Wang S (Eds.). Advances in Horticulture, vol VIII, Shanghai Jiaotong University Press, Shanghai.

Watanabe K, Tanaka T, Hotta Y, Kuramochi H, Takeuchi Y (2000). Improving salt tolerance of cotton seedling with 5-aminolevulinic acid. Plant Growth Regul 32:99-103.

Winkel-Shirley B (2002). Biosynthesis of flavonoids and effects of stress. Curr Opin Plant Biol 5:218-233.

Xu F, Cheng SY, Cheng SH, Wang Y, Du HW (2007). Time course of expression of chalcone synthase gene in Ginkgo biloba. J Plant Physiol Mol Biol 33:309-317.

Xu F, Cai R, Cheng S, Du H, Wang Y, Cheng S (2008). Molecular cloning, characterizaion and expression of phenylalanine ammonia-lyase gene from Ginkgo biloba. Afr J Biotechnol 7:721-729.

Zhang ZJ, Li HZ, Zhou WJ, Takeuchi Y, Yoneyama K (2006). Effect of 5-aminolevulinic acid on development and salt tolerance of potato (Solanum tuberosum L.) microtubers in vitro. Plant Growth Regul 49:27-34.

Zhang WF, Zhang F, Raziuddin R, Gong HJ, Yang ZM, Lu L, QF Ye, Zhou WJ (2008). Effects of 5-aminolevulinic acid on oilseed rape seedling growth under herbcicide toxicity stress. J Plant Growth Regul 27:159-169. 